\title{
DO MCONF AO VALE DO MCONF: topografias poéticas em um sistema de webconferência em meio à pandemia
}

\author{
Luciano Bedin da Costa \\ Universidade Federal do Rio Grande do Sul - UFRGS, Brasil \\ Anna Letícia Ventre \\ Universidade Federal do Rio Grande do Sul - UFRGS, Brasil
}

\begin{abstract}
Resumo
Nesse ensaio apresentamos o percurso de escrita coletiva em um sistema de webconferência chamado Mconf, entre de abril e julho de 2020, meses em que o Brasil se viu confrontado ao crescimento exponencial da pandemia relativa a Covid-19. Em meio ao principiar do distanciamento social, juntamente com a suspensão das aulas e a subsequente adesão ao Ensino Remoto Emergencial, um grupo formado por 25 estudantes de mestrado e doutorado da Universidade Federal do Rio Grande do Sul se reuniu em torno de um seminário realizado extracurricularmente e de modo virtual, voltado ao tema da poesia e suas implicações ético-políticas no contexto acadêmico. Passamos a nos referir ao Mconf enquanto Vale do Mconf na tentativa de traduzir o estranhamento e encantamento a que estávamos submetidos em nossa primeira incursão em um ensino remoto. De modo a sustentar a potência de uma escrita coletiva em modalidade virtual, são apresentados fragmentos das notas compartilhadas, recurso em que a/o(s) participantes escrevem de modo colaborativo e não identificado. Embora tenhamos vivido uma importante experiência de convivência virtual, lemos que esta não substitui o desejo em chamas de que as aulas venham a comportar novamente o calor da presença, onde possamos ativar ainda mais nossos ensejos poéticos.

Palavras-chave: Poesia; Ensino remoto emergencial; Pandemia; Escrita acadêmica.
\end{abstract}

\begin{abstract}
In this essay, we present the collective writing path on a web conference system called Mconf, between April and July 2020, months in which Brazil was faced with the exponential growth of the pandemic related to Covid-19. Amidst the beginning of social distance, together with the suspension of classes and the subsequent adherence to Emergency Remote Education, a group formed by 25 masters and doctoral students from the Federal University of Rio Grande do Sul met around a seminar held extracurricularly and in a virtual way, focused on the theme of poetry and its ethicalpolitical implications in the academic context. We now refer to Mconf as Mconf Valley in an attempt to translate the strangeness and enchantment to which we were subjected in our first experience in remote education. In order to sustain the power of collective writing in virtual mode, fragments of shared notes are presented, a resource in which the participants write in a collaborative and unidentified way. Although we have lived an important experience of virtual coexistence, we read that it does not replace the burning desire that the classes will again behave in the warmth of presence, where we can further activate our poetic opportunities.
\end{abstract}

Keywords: Poetry; Emergency remote education; Pandemic; Academic writing. 
Este ensaio foi escrito quando o Brasil contabilizava mais de 100 mil vidas ceifadas da possibilidade de luto compartilhado, dado em grande medida pela condução da pandemia às malhas da desresponsabilização e descaso por via macropolítica. Esta escrita quer marcar a memória, e sustentar nossa solidariedade às famílias.

Quando a delicadeza é uma afronta. Este é o título de um dossiê da Revista Cult, publicado em 2019, dedicado à poesia contemporânea brasileira. No breve mas belíssimo editorial assinado pelo poeta Tarso de Melo somos provocados a olhar na boca do tigre do presente e reconhecermos onde, desde a fragilidade, há uma persistência sutil e revolucionária.

Se, por um lado, aplaudo o vigor com que poetas do nosso tempo têm reagido sem rodeios, aos desafios e ataques que a democracia vem sofrendo neste país, por outro me anima perceber que, ao expor algumas "fragilidades" que, sob um olhar distraído, nada parecem dizer sobre a violência que nos cerca, se revela uma outra forma de resistência e de afronta a tudo que pretende soterrar nossa vontade de viver (MELO, 2019, p. 4).

No livro Para que poetas em tempos de terrorismos?, de Alberto Pucheu (2017), somos também incitados a pensar o exercício da poesia em tempos tão difíceis. O inusitado diálogo de abertura do livro incita uma inversão lógica no que diz respeito à posição sujeito $\mathrm{x}$ objeto em uma experiência poética: não seriam as pessoas a garantia de sobrevivência à poesia, mas é a poesia quem talvez possa garantir alguma existência às pessoas.

- a poesia morreu?

- não, ela continua bem viva, quem morreu foram as pessoas.

- mas eu vejo as pessoas por aí e não vejo a poesia.

- você vê fantasmas por aí, cadáveres que procriam, já disse um poeta há mais ou menos um século.

- se a poesia está viva, por que, então, eu não a vejo por aí?

- é difícil um fantasma ver o que de fato está vivo.

- mas você não é também um fantasma? e você não vê a poesia?

- há fantasmas que ainda conseguem vaguear pela poesia, disseminando-a e tentando com isso dar uma sobrevivência às pessoas.

(PUCHEU, 2017, p. 9).

Pensemos agora em 2020, o ano em que eclode a pandemia da Covid-19, com centenas de milhares de mortos e milhões de infectados. O que, a este presente tomado como obituário, 
a poesia poderia oferecer? Por certo não somente a beleza, a justiça ou o lirismo histórico, mas a possibilidade de uma sobrevivência, o que já nos parece alguma coisa. Lembramos imediatamente de outro Alberto, o Camus. No entanto, não traremos aqui A peste (obra recentemente revitalizada em função da pandemia), mas $O$ mito de Sísifo (CAMUS, 1989). Neste livro, Camus nos apresenta a concepção de homem absurdo, este que, diante da supressão gradual ou abrupta dos paliativos da existência (dentre estes a noção de deus, de humanismo, solidariedade), se vê lançado a um estar-no-mundo com o peso de uma lucidez assustadora. No entanto, viver a experiência de um tempo absurdo não representa para Camus uma entrega niilista ou mesmo uma reconciliação resignada.

Ocorre que os cenários se desmoronam. Levantar-se, o bonde, quatro horas de escritório ou fábrica, refeição, o bonde, quatro horas de trabalho, refeição, sono, e segunda, terça, quarta, quinta, sexta e sábado no mesmo ritmo, essa estrada se sucede facilmente a maior parte do tempo. Um dia apenas o "porque" desponta e tudo começa com esse cansaço tingido de espanto. "Começa", isso é importante. O cansaço está no final dos atos de uma vida mecânica, mas inaugura ao mesmo tempo o movimento da consciência. Ele a desperta e desafia a continuação. A continuação é o retorno inconsciente à mesma trama ou o despertar definitivo. (CAMUS, 2012, p. 27).

$\mathrm{Na}$ esteira dos múltiplos e concomitantes desmoronamentos é que entramos em 2020. Como na citação acima, múltiplos cenários desmoronam, constituem ruína com a pandemia em chamas, e com todas as aberrações políticas que a ela toma por reboque, somos literalmente confrontados a lidar com nossas continuações. Se, por um lado, reconhecemos o que somos pelo teor de nossas repetições, como experimentar um si mesmo quando o mesmo se vê subitamente subtraído? Não mais o trabalho que se tinha. Não mais o lazer que se experimentava. Não mais a casa que se habitava. Não mais a família com a qual se convivia. Não mais a universidade em que se trabalhava e se estudava. Não mais, não mais. Com o distanciamento social e o subsequente reordenamento de todas as atividades do cotidiano tivemos que nos deparar abruptamente com a ausência de determinados hábitos constituintes, ao mesmo tempo em que hábitos aparentemente sossegados se viram despertados de seu sono cotidiano. Não estar, por exemplo, de modo presencial na rotina do trabalho implicou em estar de modo até então não experimentado na casa. Sofremos, pois, de perdas como também de excessos.

No cenário da educação superior, de onde fazemos parte enquanto pesquisadoras e pesquisadores, professoras e professores, essa realidade não foi diferente. Em março de 2020, após duas semanas de aulas, as universidades se viram convocadas a suspender suas atividades presenciais. O que inicialmente estava previsto para algumas poucas semanas foi gradualmente de estendendo. A dita quarentena, inicialmente compreendida como algo provisório, foi aos poucos ganhando ares de permanência. Uma semana, um mês, um 
semestre, um ano... Diante da incerteza, uma incerteza que não teme a palavra que tropeça, a mão que treme, mas sim a palavra que quer se safar da responsabilidade, a pergunta, "quando iremos retornar?", carregada de ansiedades, medos e expectativas, foi se transformando em "como iremos retornar?". Dada a escolha pelo desastre na condução de nossa crise sanitária, fomos percebendo que a possibilidade de achatamento da curva, que situaria uma refração do número de situações acometidas pelo novo coronavírus, se reduzia a cada dia, com políticas de cuidado refratárias e uma equação de igualdade entre vida capital, escolhida pela gestão macropolítica, a retomada das atividades de forma presencial se tornava a cada dia mais distante e imprudente. Como pensar em aulas presenciais quando as estatísticas nos mostram mais de 1000 pessoas que perdem sua vida por dia e mais de 3 milhões de infectados? Com a inviabilidade do componente presencial nos vimos curtocircuitados em relação aos nossos agires costumeiros. A interrupção abrupta da relação física nos ambientes universitários atualizou de forma vigorosa fantasmas relativos à eficácia ou não das tecnologias de ensino a distância. Estaríamos, ao aderirmos às aulas virtuais, pactuando com a lógica neoliberal de precarização e privatização do ensino público superior em nosso país? Mesmo com nomenclaturas diferentes, não estaríamos a dançar a mesma música destes que veem com euforia a chegada e ascensão das faculdades $\mathrm{EaD}$ de cunho multinacional?

\section{Uma vez avariadas, o que resta às aulas?}

Em 16 março de 2020, no desenrolar da segunda semana do calendário acadêmico, a Universidade Federal do Rio Grande do Sul - UFRGS, instituição da qual fazemos parte, editou duas portarias e uma instrução normativa suspendendo as aulas e regulando as demais atividades presenciais. Segundo o artigo $1^{\circ}$ da Portaria $\mathrm{N}^{\circ} 2286$ de 17/03/2020, "as atividades de ensino presenciais no âmbito da graduação, pós-graduação stricto e lato sensu, e do Colégio de Aplicação estão suspensas de 16 de março a 05 de abril de 2020, prorrogável" (UFRGS, 2020). Já no artigo $3^{\circ}$ desta mesma resolução consta que "deve ser garantido o cumprimento dos planos de ensino e programas das disciplinas para todos os discentes". Dois pontos nos chamaram a atenção nestes dois artigos: o primeiro diz respeito ao termo "prorrogável", que discretamente finda o artigo $1^{\circ}$, e que passou a ser o termo mais utilizado nas portarias seguintes; o segundo ponto de nossa inflexão, relativo ao artigo $3^{\circ}$, diz respeito ao dever de garantir o cumprimento dos planos de ensino e programas das disciplinas iniciadas, garantia posta em xeque uma vez que o próprio semestre se via aos poucos comprometido, sob efeito das inúmeras prorrogações necessárias. Na esteira dessa complexa realidade, que de excepcional passou a ser permanente, nos vimos tomado(a)s por afetos de diferentes ordens: susto, medo, cansaço, insegurança, expectativa. No contexto da pósgraduação, tínhamos previsto a realização de um seminário de pesquisa intitulado Políticas 
do Texto V: topografias poéticas. Este seminário, vinculado ao Programa de Pós-Graduação em Psicologia Social e Institucional da UFRGS, tinha previsão de início para o final de março, num total de 10 encontros presenciais. O primeiro movimento, dado às referidas portarias, foi o de suspensão dos encontros, numa tentativa de acompanhar o andamento da pandemia e suas repercussões junto à universidade. Os vinte e cinco estudantes matriculados foram então informados acerca de tal decisão. Parecíamos todas e todos, docentes e discentes, habitar uma espécie de sursis, termo jurídico utilizado por Sartre e que dá título ao segundo livro de sua trilogia Caminhos da Liberdade (SARTRE, 1976). Se, juridicamente, sursis designa o estado de suspensão condicional de uma pena sobre a qual não se sabe ao certo quanto tempo durará, para Sartre, sursis diz respeito à flutuante e indeterminada experiência de suspensão existencial. "Tinham perdido seu antigo futuro e ainda não thes haviam dado outro: flutuavam no presente" (SARTRE, 1976, p. 74). Assim como o absurdo camusiano, a experiência de sursis apresenta-se enquanto imperativo ético, uma vez que, sem a garantia de futuro, resta ao sujeito agir ou não com o que lhe resta, ou seja, com o presente, no presente. Roland Barthes, lembrado por Giorgio Agamben, contrai, em um de seus cursos, que "o contemporâneo é o intempestivo" (AGAMBEN, 2009, p. 58). Tomando a contemporaneidade que nos veste, e dela aprendendo a tomar distância, que modos podemos aprender juntos neste intempestivo que se abre na Universidade, no que diz respeito aos efeitos desta pandemia que nos coube viver? Que futuro havia sido eliminado? O futuro de uma normalidade de semestre? De um ano acadêmico normal? Mas de que normalidade estaríamos falando? Que fraturas que se abrem e nos lançam a escrever e inscrever-nos neste nublado que se arma num ano acadêmico? Mesmo o "novo normal", terminologia bastante utilizada em nosso vocabulário pandêmico, precisaria ser inventado enquanto futuro. Sem as aulas, e sobretudo sem a experiência presencial da aula, o que restaria a professores e docentes? Que presente acadêmico restaria estando todas e todos em situação de distanciamento social? Diz-nos Agamben que perceber o escuro de nosso tempo é sermo-nos dele contemporâneo, em uma atividade de neutralizar as luzes que provém de nossa época para descobrir, nas trevas, seu escuro especial, que não é, alerta, "separável daquelas luzes" (AGAMBEN, 2009, p. 63), numa abertura de descontinuidades. Parece-nos que esta terminologia, tão usada no léxico pandêmico, 'novo normal', estaria vortejando parte das fraturas das vértebras deste tempo. Talvez este seminário esteja, em parte, dialogando com a possibilidade de fazer-com o intempestivo deste tempo que se apresenta.

Em ressonância ao imperativo ético empregado por tal sursis acadêmico, lembramos de um poema de Boaventura dos Santos, em que nos convoca a pensar a possibilidade de escolha diante de um futuro avariado.

O lado esquerdo do meu carro

avariou

perguntei ao mecânico se podia seguir viagem 
respondeu que sim desde que a viagem

fosse dentro da garagem

(SANTOS, 2015, p.22).

\begin{abstract}
Ainda muito acuados com o calamitoso futuro que se anunciava em razão da constante escolha pelo "e daí"1 e pela política da alienação e da desinformação da população por vias do governo federal diante da pandemia, resolvemos consultar as estudantes e os estudantes matriculados no seminário para uma conversa virtual. Conversa que nasce nos espaços de distanciamento social que cada uma e cada um estavam experimentando, dentro do que ainda se chamava quarentena. Local de encontro: plataforma Mconf ${ }^{2}$. Era 9 de abril. Dado a vida em seu córrego costumeiro, naquele presente de um futuro já em pretérito, estaríamos nos encontrando num bloco de estudos intitulado $(h)$ a saúde no perder-se: indulgências poéticas, cujas leituras em companhia seriam: A experiência da agonia, de Laymert Garcia dos Santos (SANTOS, 1989) e Inéditos e Dispersos, de Ana Cristina Cesar (CESAR, 1999), no espaço do teatro do Utopia e Luta, espécie de prédio-resistência localizado na região central de Porto Alegre. Era 9 de abril, e começávamos a criar uma fantasia de encontro, uma fantasia de Seminário. De algum modo, encontrávamo-nos de mãos dadas com Ana Cristina, "ancorando nosso navio no espaço" (CESAR, 2013, p.17-18). Era 9 de abril. Vivíamos a miragem de quase 18 mil infectados pelo novo coronavírus, e estávamos geograficamente distantes. Se naquele 9 de abril fantasiado, estaríamos nas escadarias que levam ao teatro, neste estávamos descobrindo os modos de manter a voz possível, e quem sabe, segurar-se nas quedas.
\end{abstract}

[14:36] boa tarde colegas

[14:40] não estamos te escutando.

[14:40] Ois

[14:41] Não sei se o meu microfone está funcionando

[14:46] Como faço para desativar meu microfone?

[14:47] naquele sinalzinho ao lado da imagem do telefone, abaixo das imagens

[14:50] simm

[15:07] a casa é uma cidade

[15:11] to aqui também!

[15:12] to por aqui sim...

$[15: 12]$ ficou ruim a chamada $=($

[15:17] oi gente, caí

[15:17] to vendo telas

[15:17] I see telas people

Fonte: fragmentos do bate-papo público de 9 abril de 2020 (os nomes dos participantes foram suprimidos). 
De algum modo, como nas escadarias, onde a travessia é aberta a qualquer uma, qualquer um, na sala virtual, a porta também permanece aberta e perene, para idas e vindas. No tutorial de uso da mesma, diz:

Configuração obrigatória de áudio no ingresso da sala: Após clicar na opção 3 do capítulo anterior, para iniciar sua reunião (abrir a sala), uma nova janela de configuração de áudio será aberta automaticamente contendo as opções que são: Opção 1: você está escolhendo falar e ouvir na reunião, ou seja, utilizar o microfone; Opção 2: você está escolhendo apenas ouvir. Nesse caso, mesmo que você tenha microfone, ele não será utilizado. Você só pode ouvir o que os outros falam, e interagir via chat. Opção 3: nunca utilize a opção 3. Ela nem deveria existir. Você não fala ou escuta, o que não faz sentido. (ROESLER, 2020, p. 6).

Nessa primeira cena de abril, a aposta era que a Opção 1 tomasse lugar, seja via voz, imagem, escrita, mesmo reconhecendo, que nossos corpos, no espaço físico da sala de aula, optem em muitas ocasiões pela Opção 2 (ser ouvinte) e pela Opção 3 (somente o registro físico de um corpo estar ali). Desde seus espaços, cada uma e cada um apresentaram-se com uma imagem-objeto, um pequeno relicário de si ao outro. As angústias, tristezas, expectativas tomaram volume. Uma pequena elegia tomava espaço. Ana Cristina nos lembraria, não sem um certo humor, que a poesia é recortada em alguns gêneros, sendo o lirismo aquele que traduz um sentimento subjetivo, sincero e pessoal; "é a linguagem do coração, do amor", diz ela, no poema Primeiras Lições (CESAR, 2013, p.18). E complementa que elegia é um dos gêneros do lirismo, a poesia que trata de assuntos tristes, quase sempre com conexão com a morte. Estávamos ali, entre elegias, e nossa intenção, enquanto docentes, era a de abrir o espaço das quintas-feiras à tarde às pessoas matriculadas, em encontros não obrigatórios e sem o compromisso curricular, no interesse de garantir um território de cuidado, em que pudéssemos constituir alguma possibilidade de futuro criativo em meio a tantas avarias. Com Boaventura dos Santos, perguntamo-nos se era ainda possível a viagem mesmo dentro de nossas garagens, sem o gesto do encontro presencial; se conseguiríamos, nesse sursis, flutuar em um presente tão abissal quanto inacreditável. Constituir uma cerca no abismo. Cercar-nos de voz, palavras, presença, partilha de uma possibilidade de cidade.

[16:17] A cidade sem tocá-la

se antes usava minhas mãos para pegar nos restos da cidade,

os papéis caídos,

se antes eu levava tudo aquilo pra casa

se antes eu acreditava em uma educação do gesto para a pesquisa,

não imaginava uma política de saúde do gesto

não toque na cidade,

não toque na cidade depois no rosto, 
não coce o olho

se antes jamais usei luvas

o meu capacete me protegia de tombos,

nunca do ar

mesmo na maior das quedas

quem é dono do ar?

Fonte: fragmento do bate-papo público de 9 de abril de 2020 (os nomes dos participantes foram suprimidos).

Uma vez que o grupo resolveu topar a aposta,

[16:59] Que bom encontrar muitos 'fantasmas que vagueiam-se pela poesia', como diria Pucheu.

[16:59] teto bom ehehehehe

[17:00] Pessoal vou me despedindo por aqui! Muito bom encontrar vocês nesse plano outro!!! Abraços!

Fonte: fragmento do bate-papo público de 9 de abril de 2020 (os nomes dos participantes foram suprimidos).

começamos a pensar nas condições desta viagem e os meios disponíveis. Olhar para o plano de ensino, avaliar o que dele poderia nos servir, o que poderia ser mantido ou adaptado. Sustentar a poesia como vasodilatador dos encontros, poesia que, segundo o poema supracitado de Alberto Pucheu, teria a capacidade de garantir alguma sobrevivência às pessoas. Alguma sobrevivência ao nós, coletivo. Com o grupo lemos a súmula e os objetivos do seminário, elaborados pré pandemia, que, de algum modo, conversava muito intimamente com o que estávamos vivenciando. Efeitos de poesia: condensar enunciações que fazem limiar ao tempo que nos é atual. As três perguntas que compunham a súmula poderiam nos servir como bússolas para nossa viagem na garagem: 1) O que marca a formação de um dizer poético que nos seja contemporâneo?; 2) Como pensar e agir poeticamente diante das urgências e improrrogabilidades do tempo presente?; 3) É possível sustentar-se poeticamente nos ditos e escritos acadêmicos?. A segunda pergunta, em especial, foi a que nos jogou a esse empreendimento de coragem, uma vez que nos convida a pensar e agir com, e não contra as urgências e improrrogabilidades. Os seis objetivos do seminário pareciam caminhar em direção a essa composição com o presente a que a nós se abria: 1) Experienciar a poesia nas zonas limiares entre o acadêmico, o político, o ético, o estético; 2) Abrir espaço para situações de leitura, interrupções, inacabamentos, equívocos; 3) Instalar bandeirolas vocais no coração das vociferações contemporâneas; 4) Praticar o cuidado na experimentação com/no Texto; 5) Laboratoriar escritas na dimensão gerúndia do coletivo; 6) Apostar na alegria como afeto político. Algumas insígnias contidas no corpo dos objetivos serviram para nós como 
horizontes de respiro, em nossa tentativa de pensar coletivamente a experiência poética de modo oblíquo. Embora não estivéssemos assentadas e assentados no território de uma PósGraduação em Letras ou em Escrita Criativa, pressentíamos que a poesia poderia operar nessas zonas limiares onde o acadêmico, o estético, o ético e o político se margeiam (objetivo 1). Se as vociferações se tornavam cada vez mais fortes e multilaterais (vociferações políticas, epidemiológicas e curriculares), a aposta nas vozes menores, nas tais bandeirolas vocais, nos parecia imprescindível (objetivo 3). Para isso, restava-nos pensar em como laboratoriar coletivamente (e de modo virtual) situações de leitura e escrita (objetivos 2 e 5) em que o cuidado (objetivo 4) e a alegria (objetivo 6) pudessem se fazer presentes.

Com os meios de que dispúnhamos, e com a pouca familiaridade em relação às tecnologias de ensino a distância, resolvemos seguir apostando nesse sítio que nos abrigou para a primeira conversa, essa ferramenta até então desconhecida, o Mconf, sobre a qual discorreremos no decorrer deste ensaio. A possibilidade de fazermos uso de múltiplas linguagens em uma mesma plataforma nos pareceu favorecer a proposta que tínhamos junto ao seminário, oferecendo ao grupo a presença por meio de imagem, áudio e escrita, sucessivamente e simultaneamente. Um exercício quase alephiano, de simultaneidade e de registro sucessivo, tal qual linguagem o é. Exercício de queda, e de sustentação de algo, um certo resto. "O que meus olhos viram foi simultâneo; o que transcreverei, sucessivo, porque a linguagem o é. Algo, contudo, recuperarei” (BORGES, 2008, p 148).

\section{Ao seminário}

Em um bonito texto intitulado Au Séminaire, publicado em 1974, Roland Barthes nos apresenta um testemunho amoroso acerca da sua experiência docente junto à École pratique des hautes études. O que lemos neste ensaio é um Barthes apaixonado pela experiência de viver-junto proporcionada nas entranhas burocráticas e administrativas da instituição. Logo no primeiro parágrafo somos presenteados por palavras que, assim como a delicadeza de Tarso de Melo (2019), afrontam discursos objetificantes acerca do dito "papel" de professor(a) e do seu "ofício" de ensinar (e não nos parece à toa o fato de papel e ofício, signos reconhecidamente apropriados pela burocracia, serem atribuídos à atividade docente).

Trata-se de um lugar real ou fictício? Nem um, nem outro. Uma instituição é tratada pelo modo utópico: traço um espaço e chamo-o seminário (...). Poderíamos dizer as coisas de outro modo: que o seminário (real) é para mim objeto de um ligeiro delírio, e que estou, literalmente, enamorado desse objeto. (BARTHES, 2004, p. 412).

Au Séminaire, em francês, traz um triplo sentido. Segundo Barthes (2004, p. 424), a expressão deve ser lida como um locativo (marcando um lugar), um elogio e uma dedicatória. 
Três também são os espaços a que Barthes (2004, p. 412 - 414) se refere quando se propõe a pensar seu seminário. O primeiro é o espaço institucional, de uma instituição que determina uma frequência, um horário, um lugar, fazendo-se impor determinadas permissões e restrições conforme níveis de hierarquia. O segundo espaço é o transferencial, o qual não se reduz à dialética vertical do professor em relação ao grupo de estudantes. Não se deixar reduzir a tal dialética não quer dizer que a transferência não exista. "O meu papel (caso exista algum) é liberar a cena onde vão estabelecer-se transferências horizontais" (BARTHES, 2004, p. 413). O terceiro espaço é o textual, de um seminário que se faz pela operação da/na linguagem, de textos quistos não como produtos (resultados de avaliações e de solicitações imperativas por parte do professor), mas enquanto práticas de escritura que podem, ou não, se fazerem enquanto produtos. De acordo com Barthes, o espaço do seminário seria da ordem do romanesco, termo não atribuído à falsidade ou mesmo sentimentalismo, sendo "somente o espaço de circulação de desejos sutis, dos desejos móveis” (2004, p. 414). Na aparente opacidade da aula é que se daria o entrecruzamento das relações amorosas, exacerbando e também extenuando a própria concepção de opacidade.

Embora com tonalidades e realidades diferentes, lembramos de Gadotti (2007) quando se refere a Paulo Freire e sua paixão por ensinar.

Paulo era muito otimista, acreditava nas pessoas e as estimulava, com suas palavras, ao engajamento e à luta por um outro mundo possível. Repetia muitas vezes que o mundo é possibilidade, não é fatalidade. A educação não é um tesouro que se perde ao "entregar" a outros. Ao contrário, é um tesouro que aumenta ao ser repartido. (GADOTTI, 2007, p. 20).

Pensar, com Barthes, o seminário enquanto experiência transferencial horizontal, e com Freire, a educação enquanto tesouro compartilhado, nos encorajou a dar continuidade aos encontros junto ao nosso grupo de estudantes desejosos de presença. Embora institucionalmente não se configurasse como um seminário formal (dado à suspensão das aulas), topamos (estudantes e professores) embarcar nessa viagem na garagem, reinventando sua topografia e convocando outros agires do corpo.

\section{Do Mconf ao Vale do Mconf}

O vale virou do avesso; quase verso. Ode.

Notas Compartilhadas sobre o Vale do Mconf, julho de 2020.

Incorreríamos em uma ilusão inócua se disséssemos que a migração para uma plataforma de ensino remoto nos foi tranquila ou mesmo cômoda. Embora compreendêssemos a 
importância do ensino a distância em determinadas circunstâncias (sobretudo em uma país continental como o nosso, onde as distâncias por vezes se colocam como verdadeiros impeditivos de aprendizagem), não nos pareceria confortável assumi-lo em um momento onde as instituições públicas de ensino superior (sejam estas estaduais ou federais) se veem ameaçadas pelo corte e contingenciamento de recursos, tendo seus espaços físicos sucateados. Ao aderirmos ao Ensino Remoto Emergencial, não estaríamos contribuindo ainda mais com a precarização do ensino presencial? O Ensino Remoto Emergencial (ERE) foi uma estratégia utilizada por inúmeras escolas e universidades para lidar com a situação do distanciamento social em virtude da pandemia. De acordo com Behar (2020),

O Ensino Remoto Emergencial e a Educação a Distância não podem ser compreendidos como sinônimos, por isso é muito importante, no contexto que estamos vivendo, clarificar esses conceitos. O termo "remoto" significa distante no espaço e se refere a um distanciamento geográfico. O ensino é considerado remoto porque os professores e alunos estão impedidos por decreto de frequentarem instituições educacionais para evitar a disseminação do vírus. É emergencial porquê do dia para noite o planejamento pedagógico para o ano letivo de 2020 teve que ser engavetado.

Afora as questões políticas, também nos assombrava a eficácia pedagógica de tais tecnologias virtuais: será que, em um sistema de webconferência como Mconf, conseguiríamos ativar tais transferências horizontais e partilhas preconizadas por Barthes e Freire? Lembramos de uma pergunta contida em um poema de Ana Martins Marques e Eduardo Jorge, indagação poética que retumbava junto às perguntas que nos fazíamos.

duas pessoas dançando

a mesma música

em dias diferentes

formam um par?

(MARQUES; JORGE, 2017, p.7).

Que música seria esta que buscávamos dançar? Estaria na melodia pensada no programa desejante do seminário? Na sistemática dos encontros? Nos textos sugeridos para leitura? E nós, dançarinas e dançarinos, estaríamos mesmo dançando em espaços diferentes uma mesma música? Talvez não se trate da mesma música, mas das conjugações possíveis do verbo dançar, de fazer dança com as aprendizagens. Assim como no espaço institucional enunciado por Barthes, tínhamos alguns contornos que poderiam garantir alguma permanência em meio ao solo pantanoso: nos encontraríamos no Mconf durante dez quintas-feiras à tarde, em encontros tangenciados por leituras específicas e pela presença de alguns convidados. Por se tratar de um seminário dedicado à poesia, tínhamos aquecido convites a dois poetas que nos 
pareciam ajudar a colocar fermentação natural às perguntas-farol do Seminário, onde, a partir de seus processos de criação, provocassem o pensamento em nossos próprios processos de escrita no contexto das pesquisas de mestrado e doutorado. Foi com Alberto Pucheu, um dos convidados, que nos demos conta acerca da música e dança que já estávamos a tamborilar (a conversa ocorreu no sétimo encontro, quando nos encaminhávamos para o último bloco). Ao falar sobre seus espaços de criação/inspiração, Pucheu nos apresenta o Vale do Socavão, localizado nos arredores da cidade de Teresópolis (RJ). Muitos de seus poemas e videoartes têm o Vale do Socavão como refrão, verdadeiras dedicatórias heterotópicas a um lugar bastante presente ao longo de sua obra.

A caminho do Vale do Socavão, sempre vejo

a placa de um outro lugar das imediações, Sumidouro.

Às vezes me pergunto: em que distância perdemos

a arte de nomear - lugares?

(PUCHEU, 2017, p. 107).

Neste fragmento de poema encontramos alguns contornos em relação ao que então passamos a chamar de Vale do Mconf. Do Mconf ao Vale do Mconf há um caminho a ser percorrido, e o simples fato de termos acesso a tal plataforma não garante a construção de tal topografia. Embora localizáveis - Socavão em Teresópolis e o Mconf em site específico ambos espaços são imagens a serem conquistadas e permanentemente atualizadas, zonas de proximidade entre o remoto e o presencial. Como no poema, situam-se próximos aos sumidouros (dado que os nomes se perdem ao longo do caminho), como também dos achadouros (uma vez perdidos os nomes oficiais, outros nomes se atiçam como numa espécie de legião). No entanto, os dois vales possuem naturezas distintas: o Socavão, rodeado de mata nativa; o Mconf, ocupado por links e ícones.

Vale habitado não apenas por nós

Por nossas escritas

Migalhas ou bandeirolas

Mas também por tudo que nos rodeia

Cada inconstância do vale

Vale(ria) a pena

Cadenciando entre o Vale e a vida

Percebemos

A vida Vale

Deve ser isso

Imensidão de um vale

Onde cabe a vida 
Fonte: fragmentos das Notas Compartilhadas sobre o Vale do Mconf, julho de 2020.

Em um primeiro sobrevoo o que se vê do Mconf é uma plataforma aparentemente inóspita, mas que oferece os recursos básicos e mais utilizados, tais como bate-papo público e compartilhamento de áudio e webcam. Em um primeiro plano de seminário, aos ares abertos da cidade, carregava-se a proposta de escrita conjunta a cada encontro, nas escadarias, ruelas, brechas de vontades de escrever com o outro no chão empoeirado da cidade. $\mathrm{Na}$ passagem ao exercício de encontro remoto, encontramo-nos com as notas compartilhadas, recurso que permite uma escrita coletiva mas não identificada. Ao contrário do bate-papo público, em que os sujeitos das postagens são revelados, em notas compartilhadas as escrituras ganham um tom de anonimato, permitindo uma circulação mais fluída em que afetos como timidez dos dedilhares, a suspeita de intimidação ao olhar do outro, autocensura - questões presentes no cotidiano de um percurso de aprendizagem também presencial - se veem diluídos, em nossa aposta de leitura, por estilhaçarem o lugar do individual, sustentando um gesto de autoria coletiva. O que percebemos ao longo de nossos encontros foi a movimentação por entre os recursos disponíveis pela plataforma, gestos que se davam em paralelo e numa coreografia atencional bastante singular. Enquanto alguém se fazia presente em imagem e som, outros se movimentavam pelo bate-papo e pelas notas compartilhadas. Movimentos por vezes convergentes (comentários acerca dos ditos e escritos pelo grupo), por vezes da ordem da deriva, deambulação, devaneio. Lembramos de Villa-Forte (2019), quando nos fala de outras experiências de percepção e reformulação do universo mental na relação que estabelecemos com as máquinas.

A forma como um dado sistema se organiza - seus comandos requeridos, atitudes permitidas, configurações de visualização e exploração - faz com que seu operador humano reformule seu universo mental, incluindo nele operações requeridas e estimuladas pela máquina. O humano, entretanto, não as direciona exclusivamente para a máquina específica. Tudo aquilo que é praticado na sua relação com a máquina passa a fazer parte da sua percepção e comportamento geral. (VILLA-FORTE, 2019, p. 101).

É evidente que a passagem do ensino presencial ao Ensino Remoto Emergencial, assim como do próprio Mconf ao Vale do Mconf, produzem também qualidades de aprendizagem e atenção diferenciadas. Lembramos novamente de Behar (2020), quando diz que "o professor de uma hora para outra teve que trocar o 'botão' para mudar de sintonia e começar a ensinar e aprender de outras formas". Levando adiante a provocação da autora, pensamos que, junto das professoras e professores, também as e os estudantes tiveram que lidar com a troca abrupta do botão de sintonia. Pensamos em Varella (2003), quando utiliza o termo 
"reencantamento do concreto" para designar outras qualidades atencionais que se produzem na relação do homem com as máquinas e suas virtualidades, afirmando que "a cognição consiste, não de representações, mas de ações corporificadas" (VARELA, 2003. p. 86). Não se trata, entretanto, de um encantamento das plataformas virtuais por parte das pessoas (agora chamadas de "usuárias" das máquinas), mas de um reencantamento da própria noção de corpo que, acoplado às plataformas, percebe suas fronteiras reconfiguradas.

Que pode o corpo diante do que não aguenta mais?

Corpo-cansado,

corpo-exausto,

corpo-esgotado.

que pode meu corpo diante da morte?

"grito de perigo lançado no meio da noite,

alagando de medo, dor e sofrimento os espaços de nossa existência", TG, Tania

Galli, em citação.

Fonte: Anotações de nossas palavras falidas I, 16 de abril de 2020.

Como pensar em fronteiras corporais e ações corporificadas quando a relação entre corpos físicos se vê apartada? De que corpos estamos falando quando participamos de encontros ou aulas virtuais? A demanda irrestrita por um corpo físico talvez seja perigosa no que diz respeito à educação a que historicamente nos submetemos, ainda bastante calcada na disciplina e docilização das ações corporais. De que corpo imprescindível estamos falando quando parte dos corpos que sentam para acompanhar nossas aulas assim o fazem de modo exausto e com pouca disponibilidade para troca? Talvez a Opção 3, citada acima, e que em tutorial diz: ": nunca utilize a opção 3. Ela nem deveria existir. Você não fala ou escuta, o que não faz sentido", tenha se sustentado em plataforma por entender que os corpos exaustos existem, seja em meio virtual e em presencial. A aposta na insistência pela presença física a todo custo talvez revele o fantasma docente e institucional de que, uma vez sem os corpos presentes em aula, nada ou pouco reste daquilo que nos acostumamos a fazer, ou que supomos saber fazer. Ainda que estejamos voltados à concepção de que o ensino a distância não deva substituir o ensino presencial, a questão que nos parece mais interessante de ser pensada é a própria noção de presença, uma presença sem condicionantes físicos ou virtuais, presença que se movimente neste jogo anacrônico com o tempo. O que é estar presente em uma aula? O que garante que uma presença se dê? Com o Vale do Mconf nos vimos instigados a experimentar outras experiências de presença, a despistar angústias e contornar ansiedades. Em alguns momentos, sobretudo nos primeiros encontros, nos víamos na posição de quem deveria convocar manifestações orais por parte do grupo, como se a fala por si só garantisse a presença desses corpos supostamente em falta. Em virtude dos problemas de conexão, ou mesmo da pouca familiaridade em relação à plataforma, parte dos participantes 
preferia ficar com a webcam desligada. Não podendo ver os rostos de todas e todos (dado que o Mconf permite apenas sete webcams ligadas), o que tínhamos para atestar tal presença era uma lista de nomes na barra lateral de nossas telas, nomes que nos diziam que as pessoas estavam logadas mas não necessariamente presentes.

Uma primeira aprendizagem docente se fez necessária a caminho do Vale, a de suportar a impossibilidade do registro visual dos corpos, registro que comporta um efeito de espera de uma fagulha de olhar. Se em uma sala de aula da universidade supomos identificar quem está presente e de que forma está presente (se cansado, disposto etc.), em uma sala do Mconf esta verificação se torna absolutamente complexa. Onde estará aquela ou aquele que não aparece? Estará com olhos vibrantes, entediados? Estará lendo e acompanhando a conversa ou disperso em outras atividades mais interessantes a si? Quantas abas de seu navegador estarão abertas e competindo com a aba do Mconf? Uma outra aprendizagem se fez necessária: no Vale do Mconf a conjunção “ou” pode não ser uma boa companheira. Assim como os múltiplos recursos que funcionam concomitantemente (bate-papo, notas compartilhadas, áudio e vídeo), múltiplas são as possibilidades de trânsito por parte das e dos participantes (entendemos que o termo participante é mais adequado do que o termo usuário, dado que não se trata de fazer uso, mas de participar de uma experiência que extrapola os domínios de um suposto sujeito usuário de um objeto alheio a si mesmo). Pode-se estar participando de um chat e escutando uma música qualquer. Pode-se escutar uma conversa ao mesmo tempo em que se lê algo aleatório. Tantos são os cruzamentos, declives e acidentes topográficos envolvidos. No Vale do Mconf é mais apropriado retirar os sapatos do "ou" e calçar as galochas do "e", estas nos permitem enfrentar com mais firmeza as superfícies desregulares e imprevisíveis.

Se nos permitirmos pousar atenção em tais aprendizagens do Vale, talvez consigamos perceber a irrupção dos corpos nas movimentações mais sutis e aparentemente irrelevantes. No Vale do Mconf os enunciados ganham outra dimensão de corporeidade quando lidos no calor de uma presença. Um simples "oi", acrescentado a uma interrogação, pode trazer um corpo inteiro quando recebe o eco de outrem (no Vale do Mconf a presença se faz em pequenas doses de sutileza e na relação com outro corpo destinado a acolhê-lo). Na topografia de um bate-papo há também o tempo enquanto presença: além dos nomes, os enunciados são precedidos pelo horário em que foram postados. Nome e tempo se fundem, fabricando um corpo outro, corpo dado a volatilidade e a permeabilidade.

[14:35] Oi povo!

[14:35] Olá pessoal, vim participar hoje.

[14:34] Vocês fizeram falta na minha tarde de quinta passada!

[14:34] Eu tb senti falta de vcs

$[14: 44]<3<3$ 
Fonte: fragmentos do bate-papo público (os nomes dos participantes foram suprimidos).

O que estes corpos voláteis e permeáveis parecem dizer é que estão ali, presentes, mas que podem a qualquer momento também não estar. É o caso da postagem do dia 7 de maio de 2020: "[14:44] Boa tarde, não consegui ativar o meu áudio, estou apenas escutando vocês! Mas estou aqui!" (grifo nosso). Grifamos a vontade de marcação de presença. A vontade de sem voz, marcar a voz, em escrita-chat.

Nas múltiplas plataformas que se enredam no Vale, há um botão que se mostrou com força, o dos silêncios. Sublinhamos aqui, e no plural, pois no Vale do Mconf os silêncios ganharam vestes polissêmicas. Por trabalharmos em superfícies diferenciadas, por vezes (e não raras) nos sentíamos, enquanto docentes, envolvidos pelo eco de nossas próprias vozes. Uma provocação lançada pela webcam não necessariamente ganhava repercussão na própria superfície audiovisual. Sob o aparente silenciamento de um rosto projetado em uma janela, burburinhos de escritura se faziam presentes por meio do chat e, sobretudo, nas notas compartilhadas. Por vezes uma câmera aberta e silenciosa deixava vazar gestos sutis de corpos envolvidos pelo trabalho dos dedos em um teclado de computador.

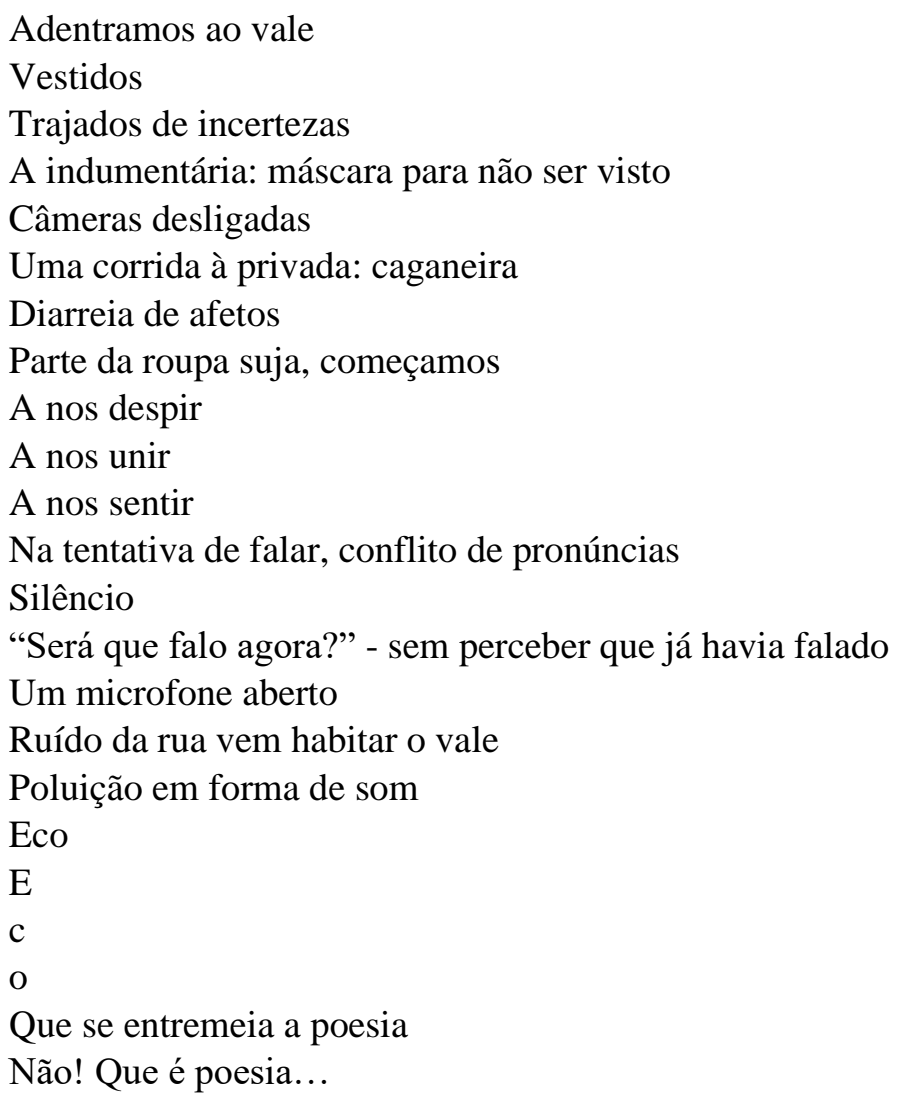


O gato mia, se esfrega e pisoteia as teclas

Pena ter apagado essa escrita

Os pássaros cantam ao fundo

Fonte: fragmentos das Notas partilhadas sobre o Vale do Mconf, julho de 2020.

A narrativa do mito de Eco, na versão transmitida por Ovídio, está entremeado ao de Narciso. A voz de Eco, para ser escutada, precisa contar com que algo faça ressoar em quem a escuta, um certo exercício de demora, de espera. O tempo para que entre boca, orelha, dedilhares, um ruído se lance. Um exercício também de queda, agora de Narciso, para quem ocupa o lugar de docência. Na experiência do Vale, algo de uma fotografia do silêncio se lançava. Diria o poeta Joan Brossa (BROSSA, 2011, p. 84-85), na única página espelhada do seu livro Escutem esse Silêncio:

\section{Només l'eco respon - Só o Eco responde \\ Només l'eco respon - Só o Eco responde}

Publicado em 1969, Brossa, entre risco e aventura, abre uma conversa de evasão, suspensão, em um escrito que cintila o tempo de regime de censura experimentado então, pelo poeta. No tempo de Vale, o regime de censura é talvez outro, situado na restrição dos corpos em chance de contato com a cidade-aula. Silêncio que talvez guarde os ecos das vidas perdidas. Em julho, já eram 82 mil.

achava-me [só]

[achava-me] quase ao acaso

achava o vale quando me perdia

seria preciso arrancar do chão uma bandeirola do caminho

flamejar o corpo com a bandeira: sos

não há caminho a trilhar em busca do vale

naqueles dias todos os caminhos levavam ao vale

há quem diga que do vale nunca se sai, uma vez que esteja dentro

talvez na memória

como um buraco negro, é do tamanho de um ponto mas acumula densidades

infinitas

nem a luz, dizem, escapa ao vale

escapo ao vale e me encontro nele

de novo e de novo

buraco negro, buraco de minhoca

o vale se espalha e contrai no tempo

contraído pela tecnologia // expandido pela poesia

e na imensidão atemporal que cada um de nós é 
pra onde o vale leva? pra onde ele nos trouxe?

Transcende ele um eu ideal que só se vale só?

Lá estava o vale

como rios que se encontram

um vale cheio confluências

bandeirolas ao vento

Fonte: fragmentos das Notas partilhadas sobre o Vale do Mconf, julho de 2020.

\section{Ruído das engrenagens: poesia e(m) notas compartilhadas}

Retomaremos aqui Au Séminaire, o apaixonado ensaio de Roland Barthes acerca da docência, em que nos apresenta o jogo infantil de "passa anel". Trata-se de uma imagem possível para pensarmos a construção de um espaço transferencial horizontal, onde "a famosa relação docente, não é a relação de quem ensina para quem é ensinado, mas a relação dos ensinados entre si" (BARTHES, 2014, p. 414). Se, por um lado, o professor continua a ser "aquele que retém, mede ou retarda a subida irreprimível da fala" (BARTHES, 2004, p.421), por outro se vê incondicionalmente submetido à dimensão sutil das transferências horizontais em que ele é mais um no jogo de passa anel, comprometido com o movimento coletivo de deslocamento da palavra (no caso das notas compartilhadas, da palavra escrita). "Corramos então risco maior: escrevamos no presente, produzamos diante dos outros (...): mostremonos em estado de enunciação". (BARTHES, 2004, p. 421)

Ao longo do Seminário Políticas do Texto V: topografias poéticas fomos percebendo que as notas compartilhadas iam ganhando um desejo e bordas de corpo a cada um dos encontros. Como no poema de Alberto Pucheu acerca do Vale do Socavão, a experiência de escrita em tais notas nos aproximava dos sumidouros, de autorias individuais que somem em detrimento de uma voz que se faz à medida que os burburinhos de escritura vão ocupando a caixa de texto disponibilizada pelo Mconf. Nas notas compartilhadas pode-se acompanhar o exato momento em que os caracteres são escritos, o processo da conquista da palavra, letra por letra, linha por linha, assim como seus recuos, recortes, colagens e supressões. Pode-se interferir no processo de construção do outro, numa dança de vai e volta, onde o tropeço faz parte da composição.

Sete foram os encontros em que nos colocamos a escrever por via das notas compartilhadas, experimentando corpos possíveis à nossa pequena comunidade composta por 25 estudantes da Pós-Graduação. No Vale do Mconf batizamos as notas compartilhadas de Anotações das nossas palavras falidas de leitura, uma vez que compreendíamos como vital certa falência dos lugares de leitura e também de escrita. No lugar das marcações individuais e localizadas, apostávamos nesse texto coletivo escrito a várias mãos e sempre em vias de se fazer, um texto produzido em ato e diante dos olhos de todas e todos. As 
Anotações das nossas palavras falidas de leitura eram gestadas na experiência do instante, em afetações e derivas oriundas das leituras prévias operadas e suas repercussões no instante presente da aula.

Uma Vida em nós. Uma presença sensível do outro em nós. Nós de corda ou de gozo?

Fonte: Anotações das nossas palavras falidas de leitura I, 23 de abril de 2020.

Em meio às múltiplas linguagens em torvelinho (oral, visual e escrita), encontramos nas Anotações das nossas palavras falidas de leitura a superfície que parecia melhor mobilizar a experiência do encanto (e por vezes do espanto) relativa a essa presença sensível do outro em nós, ao "uau" que o instante do/com o outro é capaz de acionar (é quando o nó da corda - da lei? - é capaz de ceder lugar ao nós em diferença).

é coisa.

(a origem perdida do eu)

fraturas no corpo

no "uau" do teu instante

pequenos golpes de pequenas solidões

Fonte: Anotações das nossas palavras falidas de leitura II, 07 de maio de 2020.

Poderíamos, com Barthes, chamar de diferença essa presença timbrada pela alteridade radical do desejo, uma diferença que não se apresenta na comparação de um em relação a outro (ou mesmo de um antes e um depois), mas que se engendra na própria relação, ali onde um e outro passam a interessar, não pelo que portam ou representam, mas para onde apontam.

A diferença, o que é que isso quer dizer? Que cada relação, pouco a pouco (isso demanda tempo), se originaliza: reencontra a originalidade dos corpos tomados um a um, quebra a reprodução dos papéis, a repetição dos discursos, elude toda encenação do prestígio, da rivalidade. (BARTHES, 2004, p. 15).

Nas Anotações das nossas palavras falidas de leitura percebemos a aposta em uma certa fratura da repetição discursiva, fratura operada, não por um contradiscurso (operação ainda calcada no plano discursivo), mas por uma operação poética capaz de engravidar lacunas de silêncio e ausência nestes mesmos discursos.

quem é tu que escreves comigo?

eu me pergunto sempre 




Talvez pela paisagem poética ocasionada pelas leituras e conversas com os poetas convidados, e os recursos oferecidos pelas notas compartilhadas (favorecendo uma escritura polivocal, provisória e fragmentada), foi dando-se ao nosso testemunho, para além de anotações de aula, um certo exercício poético. Jacques Lacan, diz que "há poesia toda vez que um escrito nos introduz em um mundo diferente do nosso, e, ao nos dar a presença de um ser, de uma relação fundamental, faz com que ela se torne também nossa. A poesia é criação de um sujeito assumindo uma nova relação simbólica com o mundo" (LACAN, 2008, p. 94).

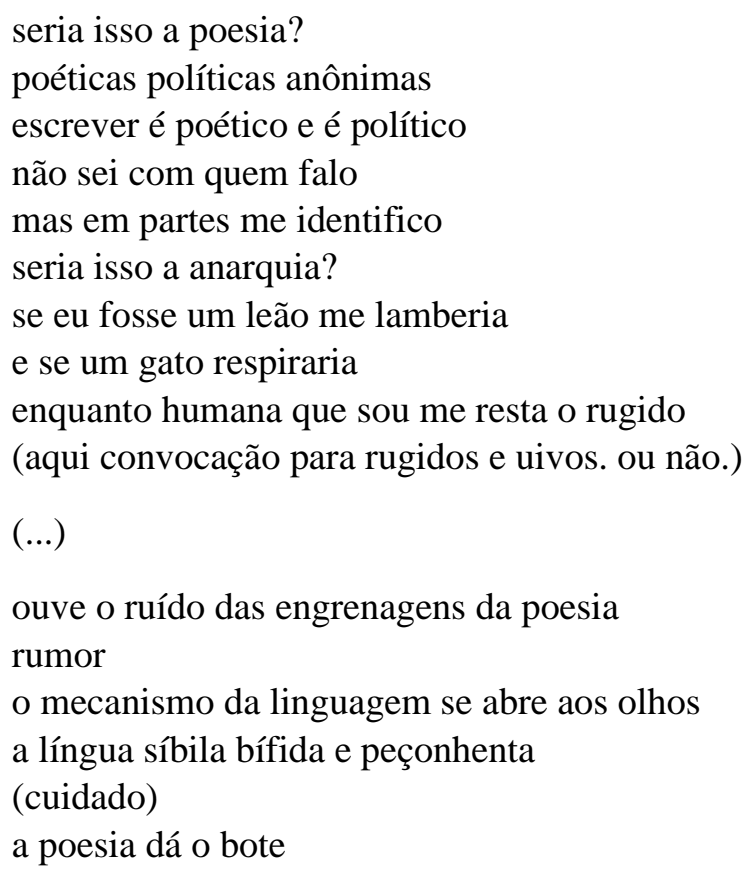

Fonte: Anotações das nossas palavras falidas de leitura IV, 28 de maio de 2020.

No Vale do Mconf a poesia é quem dá o bote na língua (sobretudo na língua maior acadêmica, esta que assenta os lugares e codifica as experiências de escritura nomeando-as de tarefa ou atividade). No work in action proporcionado pelas notas compartilhadas é possível ouvir o tal ruído das engrenagens poéticas, espécie de atividade sem atividade, tarefa sem tarefa. "La sirène succombe à sa propre voix" (Anotações das nossas palavras falidas de 
leitura IV, 18 de junho de 2020). Passamos a escrever em alerta para fazer sucumbir nossa própria voz, queda narcísica, abertura ao silêncio da tontura em um escrever-junto.



Fonte: Anotações das nossas palavras falidas de leitura III, 14 e 21 de maio de $2020 .^{3}$

Passamos a nos embriagar pela (des)graça que uma plataforma virtual pode oferecer, (des)graça sem amor e ódio a priori. Tornamo-nos, docentes e discentes, (des)graçados estudantes da poesia-em-ato em uma terra virtual, remota e inóspita. Tornamo-nos réus confessos. Nosso crime: embriagar a plataforma para que o Vale nela se erguesse em seus cumes e profundidades, cavoucando o imponente e silencioso destino que há quando se parte para uma aposta.

Destino

Atrevivência 
"o que nós queríamos é que a nossa palavra poemasse"
M.B.

Fonte: Anotações das nossas palavras falidas de leitura I, 23 de abril de 2020.

Ao buscarmos o poetizar de nossas palavras (esculpidas academicamente em matéria institucional), colocamo-nos à condição de passagem: do Ensino Remoto Emergencial passamos às Aprendizagens Remotas Emergenciais. Intuímos que nossas anotações falidas diziam e também clamavam por aprendizagens que pudessem suavizar a distância física compreendida como falta, na dimensão que aponta nosso farol desejante: topografar um viver-juntos (em s plural, tal qual o s plural dos silêncios). Escrevemos à emergência de contato e do intempestivo, em um jogo de sombra e luz. Escrevemos à altura de algum contato que nos fizesse respirar em meio a tantos dias difíceis, ao galopar das mortes noticiadas pelos jornais, sempre mais e mais.

Contato.

o artista nos contou: andar em círculos também é uma forma de avançar.

(...)

Suportar.

portar o si.

comportar o abismo.

Fonte: Anotações das nossas palavras falidas de leitura I, 23 de abril de 2020.

\section{Deve ter fim}

Era 7 de maio de 2020. O poeta paraense Rodrigo Britto veio ao Vale desdobrar uma pergunta comum: $\mathrm{O}$ escrever como acidente entre o dizer e o escutar. A poesia-coisa. Paleolíticas poéticas. Nesta conversa falamos sobre seu livro Deve ter fim (BRITTO, 2018), título que nos serviu (e que ainda nos serve) como acalanto a ser permanentemente cantado diante de tantos afetos angustiados. Era 7 de maio e contabilizávamos 9.146 mortes e mais de 135 mil casos de Covid-19 no país, números que apontavam para ausências já irrecuperáveis.

e de repente saio do balanço leve e levo um susto, quero correr, quero salvar tudo que puder, me salvar, e salvar você, e os livros, e as línguas que morrem todo dia junto com os povos em extermínio, e quero chorar, e quero passar do frio para o calor do sol, esquentar a pele, correr a linha pelo tecido, e louvar o mar, e olhar o 
horizonte, e escrever, ao mesmo tempo, tudo ao mesmo tempo, e me acalmo de novo pois me canso

ausência também é uma forma de existência, é mesmo Rodrigo.

Fonte: Anotações das nossas palavras falidas de leitura II, 07 de maio de 2020.

Em agosto de 2020, quando finalizamos esse ensaio, as vidas perdidas narradas em números estão absurdamente piores. Não mais 9 mil mortes, mas 100 mil. Não mais 135 mil casos, mas 3 milhões. Vivemos em meio a sustos, tristezas e também cansaços, esperando uma vacina que venha a inocular em nossos corpos algum tipo de esperança. Ao mesmo tempo, observamos um afrouxamento do distanciamento social, defendido por gestores preocupados com a saúde econômica. Opera-se também a retomada das atividades de ensino nas universidades públicas, efetivando o projeto de um Ensino Remoto Emergencial. O que vemos são docentes e estudantes mobilizados na teia de suas incertezas. Isso dará certo? Qual melhor plataforma a se usar? Perguntas como estas nos levam a pensar em Rolnik (2007, p.65), quando escreve que "todas as entradas são boas, desde que as saídas sejam múltiplas".

O certo é que a experiência da proposição e realização de um seminário remoto nos encorajou (nós, professores não habituados e um tanto desconfiados) a olhar com mais coragem pela fresta da janela, abrindo uma ventoinha de sensibilidade para o que, às primeiras vistas, parece ser uma terra árida, sem vinga. O que aprendemos é que o ponto de inflexão talvez não esteja nos fins, mas nos meios. Em vez de um “dará certo?", a pergunta quiçá mais amigável seja a "de que forma podemos estar presentes nisso que engendraremos com o outro?". No caso de nosso seminário, foi necessário o caminho entre o Mconf e o Vale do Mconf, a construção de um espaço comum e imaginário onde as diversas modalidades de presença e ausência pudessem se fazer presentes. A preocupação de que possamos, na medida do possível, tornar garantida a presença de todos e todas, palpita e ressoa a cada aula (principalmente quando sabemos de antemão que uma porcentagem sempre significativa das e dos estudantes de nossa Universidade não possuem acesso à internet). No Vale do Mconf vivenciamos o quanto a ocupação de um espaço virtual comporta dificuldades, mesmo para aquelas e aqueles que conseguem usufruir das condições mínimas exigidas. Há sempre uma internet instável, as demandas da casa que não escolhem tempo e espaço.

$\mathrm{O}$ fato de termos vivido uma experiência de convivência virtual desejante e pulsante, que aqueceu nossos corpos entre abril, maio, junho e principiar do gélido julho, não substitui o desejo em chamas de que nossas aulas venham a comportar novamente o calor da presença, e de que possamos, com estes, ativar ainda mais nossos ensejos poéticos. Deve ter fim então nos chega como grito-manifesto do amor que sentimos pela presença física dos corpos, de aulas que possam oferecer a possibilidade do abraço, do aperto de mão, do olhar que se furta, do murmurinho, do beijo de despedida. Deve ter fim como desejo de que as mãos sobre os teclados possam em breve carregar o café quente em direção às salas de aula, mãos que 
possam novamente encher a garrafa de água no bebedor, abrir os cadernos para anotações em suas canetas esferográficas. Deve ter fim como vontade de escutar algo para além da tocadela dos dedos junto às teclas do computador, para escutar novamente o trincolejar do molho de chaves abrindo a porta que range, a vibração grave e incômoda do ar-condicionado antigo, o ruído das cadeiras sendo arrastadas no começo da aula, a conversa alta de colegas desavisados no corredor. Deve ter fim para que venhamos a sentir o calor da lâmpada do aparelho de Datashow, o sono na primeira aula da manhã e no último período da noite.

Assim como assinala o poema de Alberto Pucheu presente no início deste ensaio, que experiências como as que vivemos junto ao Vale do Mconf permitam outras sobrevivências às aulas virtuais e também às presenciais, sobrevivências marcadas não pela exclusão de uma em relação a outra, mas por uma promessa de convivência.

M. Bethânia, por favor (me mande uma carta, só uma, pode ser de amor) eu gostaria de saber

que as coisas estão

ficando melhor, melhores.

Fonte: Anotações das nossas palavras falidas de leitura IV, 28 de maio de 2020.

\section{Notas}

1. Referência à fala do atual presidente da República Federativa do Brasil ("E daí? Lamento. Quer que eu faça o quê? Eu sou Messias, mas não faço milagre"), no dia 29 de abril de 2020, no momento em que o país, contava então com novo recorde de vidas perdidas pelo novo coronavírus. Naquele momento, 5017 mortes. Fonte: https://www1.folha.uol.com.br/equilibrioesaude/2020/04/e-dai-lamento-quer-que-eu-faca-o-quediz-bolsonaro-sobre-recorde-de-mortos-por-coronavirus.shtml. Acesso 17 ago. 2020.

2. O Mconf é um sistema de webconferência de código aberto. Inicialmente utilizado em 2010 como um projeto de pesquisa na Universidade do Rio Grande do Sul, o qual tinha por objetivo criar um sistema completo de webconferência que pudesse interoperar de forma transparente entre computadores conectados à web e dispositivos móveis em redes de telefonia. O Mconf pode ser acessado por docentes, técnicos e estudantes da UFRGS (mediante número de matrícula) e também por usuários externos (mediante link ou convite), através do site: http://mconf.org/.

3. As anotações das nossas palavras falidas de leitura III, de autoria coletiva, foram publicadas no livro Porque esperamos: notas sobre a docência, a obsolescência e o vírus (VIER et al., 2020), sob o título (a senha é amor). Disponível em: http://www.bibliotecadigital.ufrgs.br/da.php?nrb=001115604\&loc $=2020 \& \mathrm{l}=678667 \mathrm{c} 8 \mathrm{fd} 761043 . \quad$ Acesso em 17 ago. 2020.

\section{Referências}

AGAMBEN, Giorgio. O que é o contemporâneo? E outros ensaios. Chapecó: Argos, 2009, p. 55-73.

BARTHES, Roland. Au séminaire. O rumor da língua. São Paulo: Editora Martins Fontes, 2012, p. 412-424. 
BEHAR, Patrícia A. O Ensino Remoto Emergencial e a Educação a Distância. Artigo digital em site da Universidade Federal do Rio Grande do Sul. Disponível em: https:/www.ufrgs.br/coronavirus/base/artigoo-ensino-remoto-emergencial-e-a-educacao-a-distancia/. Acesso em 14 jul. 2020.

BORGES, Jorge Luis. O aleph. São Paulo: Companhia das Letras, 2008..

BRITTO, Rodrigo. Deve ter fim. Ananindeua: Edições 1/4, 2018.

BROSSA, Joan. Escutem esse silêncio. São Paulo: Lumme, 2011.

CAMUS, Albert. Mito de Sísifo. Rio de Janeiro: BestBolso, 2012.

CESAR, Ana Cristina. Inéditos e Dispersos. São Paulo: Ed. Ática, 1999.

Poética. São Paulo: Companhia das Letras, 2013.

GADOTTI, Moacir. A escola e o professor: Paulo Freire e a paixão de ensinar. São Paulo: Publisher Brasil, 2007. Disponível em: http://acervo.paulofreire.org:8080/xmlui/handle/7891/2773. Acesso em 11 ago. 2020.

LACAN, Jacques. As Psicoses - Seminário 3. São Paulo: Zahar Editores, 2008.

MARQUES, Ana Martins. JORGE, Eduardo. Como se fosse a casa (uma correspondência). Belo Horizonte: Relicário Edições, 2017.

MELO, Tarso de. Quando a delicadeza é uma afronta (org). Cult: Antologia Poética. São Paulo, N.2, nov. 2019.

PUCHEU, Alberto. Para que poetas em tempos de terrorismos?. Rio de Janeiro: Azougue Editorial, 2017.

ROESLER, Valter. Tutorial de uso do Mconf na UFRGS. Porto Alegre: UFRGS, 2020. Disponível em: https://www.inf.ufrgs.br/ roesler/UFRGS/TutorialMconf/Tutorial_MconfUFRGS.pdf. Acesso em 5 ago. 2020.

ROLNIK, Suely. Cartografia sentimental: transformações contemporâneas do desejo. Porto Alegre: Sulina: Ed. UFRGS, 2007.

SANTOS, Boaventura de Sousa. 139 epigramas para sentimentalizar pedras. Rio de Janeiro: Confraria do Vento, 2015.

SANTOS, Laymert Garcia dos. A experiência da agonia. In: Companhia das Letras, 1989.

SARTRE, Jean-Paul. Sursis. São Paulo: Círculo do Livro, 1976.

UFRGS. Mconf: Serviço de webconferência. Porto Alegre: UFRGS. Acesso em: https://mconf.ufrgs.br/. 4 ago. 2020.

UFRGS. Portaria $\mathbf{n}^{\circ}$ 2286, de 17 de março de 2020. Suspende atividades presenciais de ensino na Universidade. Site da UFRGS. Porto Alegre, RS, 17 mar. 2020. 1p. Disponível em: https://www.ufrgs.br/dequi/wp-content/uploads/Portaria_UFRGS_2286.pdf. Acesso em 8 ago. 2020.

VARELA, Francisco J. Reencantamento do concreto. In: LANCETTI, Antônio (dir). O reencantamento do concreto. Núcleo de Estudos da Subjetividade do Programa de Estudos Pós-Graduados em Psicologia Clínica da PUC-SP. São Paulo: Huccitec, 2003, p. 71-86.

SANT'ANNA Jr, Ademiel et al. (a senha é amor). In: VIER, Angélica. COSTA; Cristiano B. LULKIN; Sério (org). Porque esperamos: notas sobre a docência, a obsolescência e o vírus. Porto Alegre: Edições Autonomaz; UFRGS, 2020, p. 60-67. Disponível http://www.bibliotecadigital.ufrgs.br/da.php?nrb=001115604\&loc=2020\&l=678667c8fd761043. Acesso em 17 ago. 2020.

VILLA-FORTES, Leonardo. Escrever sem escrever: literatura e apropriação no século XXI. Rio de Janeiro: Ed. Puc-RIO; Belo Horizonte: Relicário, 2019. 


\section{Correspondência}

Luciano Bedin da Costa: Docente da Faculdade de Educação e do Programa de Pós-Graduação em Psicologia Social e Institucional da Universidade Federal do Rio Grande do Sul - UFRGS. Coordenador do Grupo de Pesquisa Políticas do Texto.

E-mail: Bedin.costa@gmail.com

Orcid: https://orcid.org/0000-0002-6350-2644

Anna Letícia Ventre: Psicanalista, Mestra em Psicanálise: clínica e cultura - UFRGS, doutoranda no Programa de Pós-Graduação em Psicologia Social e Institucional - UFRGS. Faz parte do Grupo de Pesquisa Políticas do Texto.

E-mail: annaleticiaventre@gmail.com

Orcid: https://orcid.org/0000-0001-7722-0050

Texto publicado em Currículo sem Fronteiras com autorização dos autores. 